\title{
The Relationship Between Grade 11 Students' Achievement in Trigonometric Functions and Their Teachers' Content Knowledge
}

\author{
Ugorji I. Ogbonnaya, Ph.D \\ Department of Maths, Science \& Technology Education \\ Tshwane University of Technology, South Africa \\ ogbonnayaui@tut.ac.za \\ David Mogari, Ph.D \\ Institute for Science \& Technology Education \\ University of South Africa \\ mogarld@unisa.ac.za
}

\section{Doi:10.5901/mjss.2014.v5n4p443}

\begin{abstract}
The study investigates the relationship between grade 11 students' achievement in trigonometric functions and their teachers 'content knowledge of trigonometric functions. The aim was to know if students' poor achievement in trigonometric functions was as a result of teachers' lack of content knowledge of the topic. All participants wrote the same cognitive test that was aligned with the relevant curriculum. Pearson product moment index showed a statistically significant relationship between student achievement and teacher content knowledge and linear regression analysis indicated that $76.8 \%$ of the variation in the student achievement is explained by teacher content knowledge. The study affirms the importance of teacher content knowledge in student learning.
\end{abstract}

Keywords: Student achievement; teacher content knowledge; trigonometric functions

\section{Introduction}

Among others, trigonometry can be perceived as a component of mathematics that studies triangles and how the sides and angles of triangles relate. Trigonometric functions are used to describe the relationships between angles and sides of triangles. According to Tuna (2013) trigonometry improves students' cognitive skills and has great use in daily life. The South African Curriculum (see Department of Education [DoE], 2003, p23) stipulates that the teaching of trigonometric functions at Grade 11 should enable students to do the following:

i. Demonstrate the ability to work with various types of functions including:

$y=\sin (k x) ; y=\cos (k x) ; y=\tan (k x) ; y=\sin (x+p) ; y=\cos (x+p) ; y=\tan (x+p)$;

$y=a \sin (x)+q ; y=a \cos (x)+q ;$ and $y=a \tan (x)+q$

ii. Recognise relationships between variables in terms of numerical, graphical, verbal and symbolic representations and convert flexibly between these representations.

iii. Generate as many graphs as necessary, initially by means of point-by-point plotting, supported by available technology, to make and test conjectures about the effect of the parameters $k, p, a$ and $q$ for functions including those listed above.

iv. Identify the domain and range; the intercepts with axes; the asymptotes; the shape and symmetry; and periodicity and amplitude. Hence use applicable characteristics to sketch graphs of trigonometric functions.

Tuna (2013) asserts that trigonometry provides transition from algebra to geometry. On the other hand, The Nuffield Foundation (2013) considers aspects of algebra and geometry as pre-requisite knowledge for trigonometric functions. The Nuffield Foundation further explains that it is in trigonometry where students come across, for the first time, functions represented by name instead of a polynomial with a symbol such as $x$ and this tends to pose challenges to students because they first have to relate triangles to numerical relationships and then manipulate the symbols. De Villiers and Jugmohan (2012) mention that "learners have little understanding of underlying trigonometric principles thus resort to memorising and applying procedures and rules, while their procedural success masks underlying conceptual 
gaps or difficulties" ( $p$ 9). The grade 12 mathematics students in the Gauteng province (i.e. one of the nine provinces in South Africa) had difficulties with trigonometric functions in the 2012 end-of-year examination (see Chauke, 2013). Tuna (2013) has documented studies that have discussed difficulties posed by trigonometry to students.

In order to improve students' achievement (SA) in trigonometry it is important to advance our understanding of the factors that contribute to students' learning. Understanding the reasons for students' poor achievement may be the first step to designing a necessary effective intervention initiative to address the issues of students' poor achievement. This study therefore explores the relationship between grade 11 students' achievement and their teachers' content knowledge of trigonometric functions. This will be done by answering the following questions:

i. Is grade 11 students' achievement related to their teachers' content knowledge of trigonometric functions?

ii. To what extent can teachers' content knowledge of trigonometric functions predict the students' achievement in trigonometric functions?

\section{Relationship between Student Achievement and Teacher Content Knowledge}

Research on the relationship between teacher content knowledge and student achievement dates back to the $20^{\text {th }}$ century and is considerably documented. For example, Strauss and Sawyer (1986) used average teachers' scores at district level on a National Teacher Examination to estimate teacher content knowledge and average students' test scores to estimate students' achievement in North Carolina, United States. Strauss and Sawyer found a strong positive correlation between the average teachers' score and the average students' score. A similar study was conducted by Ferguson (1991) using average teachers' scores at district level on a state teacher licensure test in over 900 districts in Texas, United States and students' average test scores in the district. Ferguson also found a positive relationship between teachers' average test scores and students average test scores. The study further reported that teachers' score accounted for 20 - 25 percent variation in students' average scores in the districts. We note the use of teachers' and students' average test scores at district level as a limitation of the studies by Strauss and Sawyer (1986) and Ferguson (1991). The presence of outliers in the data could lead to overestimation of the effect of teacher content knowledge on student achievement. Our study overcomes the limitation by using individual cognitive test scores of teachers and students.

On the other hand, Boyd, Lankford, Loeb, Rockoff and Wyckoff (2008) studied the effects of pathways into teaching in New York City using data on students and teachers in grades $3-8$. The study showed that teachers' scores on verbal and literary ability licensure tests correlate positively with students' achievement. Baumert, Kunter, Blum, Brunner, Voss, Jordan, Klusmann, Krauss, Neubrand and Tsai (2010) indicate that teachers' knowledge in mathematics correlates with their students' achievement while inconsistent results were found in other school subjects. Hill, Rowan and Ball (2005) and Hanssen (2006) used the same measures of teacher mathematics content knowledge to predict student achievement in mathematics. Hill et al (2005) found a significant relationship between teachers' mathematical knowledge and student achievement gains after controlling for key student-level and teacher-level covariates. Hanssen (2006) who had hypothesized that education, experience, and professional development hours are predictors of mathematical knowledge for teaching (MKT), classroom practice and student achievement, found that only MKT and student achievement had a statistically significant relationship. Tchoshanov (2011) compared middle grades teacher knowledge of number sense; algebra; geometry and measurement; and probability and statistics with that of their students in the same topics. Research programme conducted at the Max Planck Institute for Human Development investigated the significance of secondary teachers' mathematics content knowledge for their students' achievement (see Baumert, Kunter, Blum, Brunner, Voss, Jordan, Klusmann, Krauss, Neubrand \& Tsai, 2010; Kleickmann, Richter, Kunter, Elsner, Besser, Krauss \& Baumert, 2013).

However, except for Baumert et al. (2010) none of the afore-mentioned studies were conducted in senior classes. Goe and Stickler (2008) emphasises that teacher content knowledge is essential for student learning particularly in secondary classes, even though it is acknowledged that a teacher may have strong teacher content knowledge and yet have her/his students achieving poorly. To this end, Shulman (1986) indicates that successful mathematics teaching is a function of teacher content knowledge, pedagogical knowledge as well as pedagogical content knowledge. Notably, none of all the above studies focused solely on content knowledge of trigonometry particularly trigonometric functions nor were any conducted in South Africa where there are schools with teaching and learning problems particularly in trigonometry (see, for example, Chauke, 2013; De Villiers \& Jugmohan, 2012). There is therefore the need to investigate the relationship between SA and TCK on trigonometric functions. 


\section{Conceptual Background}

Numerous factors play a role in the teaching and learning equation (cf. Goe \& Stickler, 2008; Mogari, Kriek, Stols \& Ogbonnaya, 2009). Among such factors are teacher background (teacher qualification and experience), teacher belief, teacher knowledge (content knowledge and pedagogical content knowledge) and school and student contextual factors (Rohaan, Taconis \& Jochems, 2010; Beswick, 2012; Khader, 2012; Ingvarson, Beavis, Bishop, Peck \& Elsworth, 2004). These factors impact either directly or indirectly on teachers' teaching and students' learning and achievement. However, the focus in this study is on the relationship between teachers' content knowledge and students' achievement.

\subsection{Teacher content knowledge}

Ball, Thames and Phelps (2008), drawing from Shulman's (1986) notion of pedagogical content knowledge, tried to develop a practice-based theory of content knowledge for teaching. They categorised content knowledge into common content knowledge (CCK), horizon content knowledge (HCK) and specialised content knowledge (SCK). CCK is the knowledge of the topics and procedures, it is "the mathematical knowledge known and used in common with others who know and use mathematics" (Ball et al., 2008, p 403). CCK is what Leinhardt and Smith (1985) and Grossman (1990) earlier identified as content knowledge. HCK is knowledge of mathematics topics in the curriculum and how they are related while SCK is mathematical knowledge needed for teaching. Ball et al. acknowledged the centrality of CCK in SCK because a teacher needs to know the content of the curriculum to be able to show students how to solve problems. According to Baumert et al. (2010), content knowledge remains inert in teaching unless it is "accompanied by a rich repertoire of mathematical knowledge and skills relating directly to the curriculum, instruction and students' learning" (p139).

Leinhardt and Smith (1985) conceptualised content knowledge as the knowledge of "concepts, algorithmic operations, the connections among different procedures, the subset of the number system being drawn upon, the understanding of classes of student errors, and curricular presentations" ( $p$ 247). CK encompasses conceptual and procedural knowledge and understanding of the nature and structure of the subject, on the other hand (Grossman, 1990). Conceptual knowledge is knowledge of facts, principles and theories. In this study, teacher content knowledge (TCK) refers to the teachers' knowledge of trigonometric functions particularly the concepts such as period, frequency, amplitude and asymptote of trigonometric functions. Procedural knowledge of trigonometric functions is concerned with knowledge of steps to solve trigonometric functions problems, for example, knowledge of the steps to calculate the frequency of a trigonometric function when the period is given. Understanding the nature of the subject has to do with perception of trigonometric functions, for example, understanding the difference between trigonometric functions and other functions. Understanding the structure of the subject is knowledge about the hierarchy of ideas and concepts, and knowledge about the rules or methods that prescribe how to make and evaluate claims in trigonometric functions (Grossman, 1990).

\subsection{Evaluation of teacher content knowledge}

The evaluation of teachers' content knowledge is a contentious issue. Knowledge is intangible; hence education researchers use various objective markers that are tangible and practical as proxy measures of teacher content knowledge. For example, Rice (2003) used teachers' level of qualifications as marker for content knowledge, DarlingHammound (2000); Greenberg, Rhodes, Ye and Stancavage (2004); Wenglinsky (2002), and Wilson and Floden (2003) used subject majors as measures of teacher knowledge, and some other studies used teachers' coursework coverage or grade points average (GPA) at college or university.

The assumption behind the use of the proxy measures is that teachers with higher GPAs, for example, or those who covered more mathematics courses at college or university, or even those teachers who majored in mathematics will likely have more content knowledge than their counterparts with lower GPAs or who covered fewer courses at college or university, or did not major in mathematics. However, one major shortcoming with the use of the indirect or proxy measures is that variations in the quality of education, content coverage, and training activities could mean that teachers with the same paper credentials possess different levels of content knowledge. The proxy measures do not give clearly what teachers know (Ball, Lubienski \& Mewborn, 2001). We therefore argue that the use of proxy measure in evaluating teacher knowledge of trigonometric functions does not clearly indicate the level of teacher's knowledge of trigonometric functions. 
In contrast, the use of cognitive tests to measure teachers' content knowledge provides direct measures of the teachers' knowledge in a content domain (Mullens, Murnane \& Willett, 1996). Recently, there are studies that have also used cognitive test as a measure of teacher's content knowledge (see, for example, Hill et al, 2005; Krauss, Brunner, Kunter, Baumert, Blum, Neubrand \& Jordan, 2008; Baumert et al, 2010). According to Ahn and Choi (2004) cognitive test seems to give control over the actual content being measured. The use of tests to evaluate teachers' content knowledge is hinged on the assumption that the quality of a teacher's content knowledge can best be judged when it is directly tested. Moreover, as argued by Odden, Borman and Fermanich (2004) standard based teacher test scores could be useful in research on teacher effects on student learning. It is our view that teachers' scores from well designed, practice based teacher evaluation system provide better measures of TCK. Hence, our study used a cognitive test to measure teachers' content knowledge of trigonometric functions.

Furthermore, it is worth noting that evaluating teachers' content knowledge continues to be a challenge particularly that higher student achievement cannot solely be attributed to sound teachers' content knowledge. Simply because, in Shulman's (1986) model of PCK, content knowledge is a component thereof and factoring it out tends to be problematic. According to Hill, Schilling and Ball (2004) teachers' content knowledge (TCK) and pedagogical content knowledge (PCK) are merged into single body of knowledge. On the other hand, Krauss et al (2008) concluded that even though CK and PCK were significantly related they were separable and unique domains of knowledge. Kleickmann et al (2013: 91) report that 'there is some preliminary evidence for the notion that CK might be a pre-requisite for PCK development' (p91). Drawing from the forgoing discussion it is reasonable to think that it is possible to measure teachers' CK separately, but isolating it from other factors in the teaching-and-learning setting remains a challenge particularly when attempting to establish a link between TCK and SA. In order to circumvent this challenge our study measures TCK before the teachers taught trigonometric functions because a possibility exist that TCK is improved over the duration of the course and the extent of improvement of TCK may differ from teacher to teacher. Also, the study uses teachers who were comparable to some extent in the sense that they largely worked co-operatively and were subjected to the same monitoring system.

\subsection{Student achievement}

Student achievement on a cognitive test is taken as a measure of students' knowledge of trigonometric functions. It is however our view that student knowledge is complex that is shaped by factors such as teachers' content knowledge (TCK) and practices, students' socioeconomic backgrounds, school resources, students' interest, attitudes and so on. According to Kupermintz (2002), factors that influence what a student knows at the point in time are dynamic and interact as well. Teacher content knowledge is of vital importance in teaching because it influences learning (see, for example, Hill, Rowan \& Ball, 2005; Hanssen, 2006; Rockoff, Jacob, Kane \& Staiger, 2008; Rohaan, Taconis \& Jochems, 2010; Wessels \& Nieuwoudt, 2010). Spaull (2012) argues that teacher content knowledge is far more important than other factors in teaching because students cannot learn unless there is a teacher in the class to teach them, and teachers cannot teach what they do not know. We note that the teacher interprets the curriculum and then determines what to teach, what not to teach and how to teach those aspects of the curriculum. Furthermore, in order for the teacher to perform all these functions as expected, content knowledge is critical. We therefore assert that students' learning is a function of teacher content knowledge, among others. Hence, the focus of our study is on the relationship between TCK and $\mathrm{SA}$ in trigonometric functions.

\section{Methodology}

\subsection{Participants and research approach}

This is a correlational study that involved a convenient sample of 19 teachers and their respective 418 grade 11 students of schools based in an education district in North West province, South Africa. The district has a well-established and active school monitoring system. The schools are largely of comparable socio-economic conditions, teach same curriculum and write same end-of-year examination. The teachers' teaching experiences range from 6 to 21 years and their qualifications are from a three year college of education diploma to a non-cognate master's degree. None of the teachers had a postgraduate academic mathematics background. The teachers belong to the same cluster where they meet at least twice a month to share their curriculum implementation experiences and to discuss ways to improve their teaching. Arguably, by implication the students seem to have level of knowledge of trigonometric functions. 


\subsection{Instruments}

A cognitive test was used to evaluate teachers' content knowledge and measure the students' achievement. Teachers and students wrote the same test to enable better comparison of scores as this provided a better insight into the relationship between teacher content knowledge and student achievement.

\subsection{Development of the test}

In order to draw credible inferences from the study the cognitive test was based and aligned with aspects of the curriculum the teachers teach and students learn (Ahn \& Choi, 2004; La Marca, 2001). La Marca (2001) opined that content match and depth match are the two major dimensions of assessing instrument alignment. Content match checks how well test content matches subject area content in the sense that it addresses the broad curriculum standard, the objectives of the curriculum and reflects major emphasis and priorities of the curriculum. Depth match checks how well the test matches the knowledge and skills of the curriculum standard in terms of complexity. The degree of content and depth match of the test with the aspects of curriculum was determined as follows:

Step 1: It was imperative to first establish a conceptual framework for the test by identifying the specific mathematics content of trigonometric functions from the curriculum. This was achieved by analysing the trigonometric functions content and depth using taxonomical categorisation of content complexity provided by the department of Education (DoE, 2008).

Content complexity is used to differentiate learning expectations and outcomes by considering the amount of prior knowledge, processing of concepts and skills, perceived cognitive demand required, discipline sophistication, number of parts, reasoning, generalization, and application of content structure necessary to meet an expectation or to attain an outcome (Webb, 2010). According to Webb, content complexity is an important factor when considering tasks students perform, the instructional experiences teachers shape for students, and the relationship among different components of the instructional system. It is frequently used to express a range of levels from simple to high engagement in doing mathematics.

The South African mathematics assessment guidelines for Grade 10 -12 (DoE, 2008), used a variation of Bloom's taxonomy to categorise the content complexity of mathematics examination questions at the Further Education and Training (FET) band. The categories are four and are as follows:

$\begin{array}{ll}\text { Level } & \text { Content Complexity } \\ 1 & \text { knowledge (recall) } \\ 2 & \text { performing routine procedures } \\ 3 & \text { performing complex procedures } \\ 4 & \text { problem solving }\end{array}$

The categories can be thought of as levels of complexity of the questions that increase from recall to problem solving questions. Recall and performing routine procedures demand low-level cognitive skills while performing complex procedures and problem solving demand high-level cognitive skills such as critical and creative thinking skills (Boston \& Smith, 2009).

Step 2: A pool of questions to assess the content knowledge of the topic was generated. The pool included questions from the four content complexity categories (knowledge, performing routine procedures, performing complex procedures, and problem solving) discussed in step 1. The questions were scrutinised and vetted by 3 senior high school mathematics teachers of non-participating schools and 2 mathematics curriculum advisers. They checked the appropriateness of the responses that the items elicited in line with the curriculum, verified whether the questions covered the curriculum and also verified the weighting of the questions.

Step 3: The test was further validated by another 3 senior high school mathematics teachers and 2 mathematics education specialists who judged the level of relevance of each question in line with the Curriculum using a four point rating scale $(1=$ not relevant; $2=$ fairly relevant; $3=$ relevant; $4=$ highly relevant). All questions were retained because they all had a minimum average rating of 3,5.

Step 4: The test was piloted with five teachers and 40 students from another district.

Step 5: Two senior teachers who took part in the validation scored the pilot test. Based on their observation of the answers they made some recommendations. For example, they recommended that the domain of the question: 
Use the graphs to solve the equation: $\cos 2 k-1=\frac{\sin k}{\cos k}$ if $k \varepsilon\left[-360^{\circ} ; 360^{\circ}\right]$ be limited to $\mathrm{k} \in\left[-180^{\circ} ; 180^{\circ}\right]$

\subsection{Validity and reliability of the test}

The validity (content and construct) of the test was established through the vetting and content complexity analysis processes discussed above. The reliability was established by using Kuder-Richardson 21 formula (Cohen, Manion \& Morrison, 2007), which yielded a coefficient of 0.92 at $99 \%$ confidence interval. The results implied that the test instrument was reliable.

\subsection{Data collection}

The first author visited the participants in their respective schools to administer the test. The teachers wrote the test before they taught trigonometric functions and students wrote the test after the course.

\section{Findings}

Table 1 presents the respective descriptive statistics of teachers' and students' scores.

Table 1: Descriptive statistics of teachers' and students' scores

\begin{tabular}{|c|c|c|c|c|c|}
\hline \multirow{2}{*}{ Variable } & \multirow{2}{*}{$\mathrm{N}$} & \multirow{2}{*}{ Mean } & \multicolumn{2}{|c|}{ Highest possible score is 60} & \multirow{2}{*}{ Mean std deviation } \\
\hline & & & Lowest score obtained & Highest score obtained & \\
\hline Teachers & 19 & 36.82 & 17 & 54 & 14.42 \\
\hline Students & 418 & 20.45 & 0 & 49 & 10.61 \\
\hline
\end{tabular}

The results in table 1 show that the teachers outperformed their students.

Pearson's product-moment correlation coefficient between the teachers' and the students' scores was calculated using SPSS at 99\% confidence interval. Table 2 shows the correlation matrix of Pearson's product-moment correlation between teacher content knowledge and student achievement.

Table 2: Pearson product-moment correlation between teacher content knowledge and students' achievement

\begin{tabular}{cc}
\hline Variables & Teacher Content Knowledge \\
\hline Student achievement & $0.876^{\star}$ \\
\hline${ }^{*}$ Correlation is significant at $p<0.01$ &
\end{tabular}

The result in Table 2 shows a statistically significant positive relationship between teachers' content knowledge of trigonometric functions and their students' achievement in trigonometric functions.

In order to estimate how the independent variable (teacher content knowledge) predicts the dependent variable (student achievement), linear regression analysis of the two variables was performed.

The result of the linear regression analysis is displayed in Table 3. The Table shows the SPSS output of the model summary showing R (the correlation between the observed and predicted values of students' achievement), R square, adjusted $\mathrm{R}$ square and the standard error. $\mathrm{R}$ square is the coefficient of determination; it is the proportion of variation in students' achievement explained by teachers' content knowledge.

Table 3: Model summary of linear regression analysis of teachers' content knowledge and students' achievement

\begin{tabular}{ccccc}
\hline Model & $\mathrm{R}$ & R Square & $\begin{array}{c}\text { Adjusted } \\
\text { R Square }\end{array}$ & $\begin{array}{c}\text { Std. Error of } \\
\text { the Estimate }\end{array}$ \\
\hline 1 & $0.876 a$ & 0.768 & 0.742 & 4.364057585 \\
\hline
\end{tabular}

The value of $\mathrm{R}$ square $(0.768)$ implies that $76.8 \%$ of the variation in the students' achievement in trigonometric functions is explained by teachers' content knowledge. 


\section{Discussion}

The findings show that teacher content knowledge of trigonometric functions is positively and significantly related to student achievement. The results further show that $76.8 \%$ variation in student achievement in trigonometric functions can be attributed to teacher content knowledge. The results are consonant with those by Hill et al (2005); Hanssen (2006); Boyd et al (2008) and Rockoff et al (2008). This implies that, conversely, there is a relationship between students' poor achievement in trigonometric functions and teachers' lack of content knowledge of the topic. Rohaan, Taconis and Jochems (2010) indicate that an effective teacher relies heavily on the content he/she understands. We therefore affirm that a teacher with good mastery of content knowledge is able to organise and arrange the content she/he is going to teach in such a way that it can be learned meaningfully, and such a teacher is able to anticipate and correct students' learning misconceptions, errors and difficulties. On the other hand, a teacher with limited content knowledge is likely not to be able to extricate the subject content to the understanding of the students.

A teacher with content knowledge that is limited to mathematical procedures only, as observed by Tchoshanov (2011), will have less opportunity to influence students' success. Simply because a teacher's PCK, among others, depends on TCK. It is therefore unlikely for a teacher to expose students to complex procedures and problem solving that demand high-level cognitive skills when the teacher himself/herself cannot handle problems that demand complex procedures and high-level cognitive skills.

The findings also show that teachers outperformed their students. The result is consistent with the view by Shulman (1986) that it is vital that teachers know more than their students if they are to be effective teachers. We therefore state that teachers need to be deep rooted in mathematical concepts and applications in order to enable students to develop conceptual understanding of content and to apply the content in real situations. This possibly explains why research tends to portend a positive relationship between teacher content knowledge and student achievement. This could also throw more light on the current debate about the state of mathematics teaching and learning in the country especially in the light of the recent paradoxical revelation that $62 \%$ of grade 6 mathematics teachers in a study could not answer a mathematics question at the 6th grade level (Spaull, 2012).

This also may explain why some teachers tend to avoid teaching some parts of the curriculum or topics. If a teacher lacks the content mastery of a topic or curriculum content, he will likely not go beyond the rudimentary level of the topic which will only expose the students to the lowest level of content complexity in that topic or subject. Students taught by such a teacher will not easily answer questions at the higher levels of content complexity and as such will not easily achieve good results in any standard examination as they may only be able to attend to questions at the recall level.

Another issue to note from the study is the use of a cognitive test to measure teacher content knowledge. This is a departure from a tendency to measure teacher content knowledge using proxies as evident in various studies (see, for example, Darling-Hammound, 2000; Wenglinsky, 2002; Rice, 2003; Wilson \& Floden, 2003; Greenberg et al, 2004; Goe \& Stickler, 2008). Phelps and Schilling (2004) indicate that proxies tend to consider a more general content knowledge rather than knowledge specific to a particular area of curriculum which can be directly measured with a relevant test. Hence, there are studies that support the idea of using test scores as a direct measure of teacher content knowledge (see, for example, Mullens et al, 1996; Ball et al, 2001; Ahn \& Choi, 2004; Hill et al, 2005). The cognitive test we used provided us with an acceptable measure of teacher content knowledge of trigonometric functions, and subjecting students to the same test even enabled us to more directly compare the actual achievement of teachers and students.

\section{Conclusion}

As the study has shown that teacher content knowledge of trigonometric functions is related to student achievement in the topic and $76.8 \%$ of the variation in the students' achievement in trigonometric functions is explained by teachers' content knowledge, it therefore means that if the achievement of students in mathematics is to improve a starting point is to improve practising teachers' knowledge of the subject. One way of achieving this is to mount concerted subject content workshops for the practising teachers. This is particularly important taking into consideration that the subject matter inadequacies of some teacher education colleges in the past. To effectively carry out such workshops for teachers, there may be need to embark on wide range of training needs assessments of the teacher content knowledge. This will make each workshop to be tailor-made and properly channelled to suit specific categories of teachers.

Some studies (e.g. Franke, 2002; Garet, Porter, Desimone, Birman and Yoon, 2001) show that teacher development workshops that are focused on content that the teachers teach and that are long termed are positively 
related to students' achievement. Therefore, the duration of the recommended teacher development workshops should be long enough to enable proper coverage of the content. It may not be beneficial that many topics are covered in a one or two days' workshop and the teachers leave the workshop not having improved on their content knowledge. Teachers need regular content training on some topics (including trigonometric functions) in order to improve on their teaching. Nevertheless, the use of 19 teachers in a quantitative study is a limitation. Perhaps there might be a need to repeat the study using much larger samples of participants. Another limitation is that there are other factors that can directly or indirectly influence student learning which we did not control. Probably, the result would have been different had we controlled the factors. It would therefore be of interest to repeat the study with the aforesaid factors fixed.

\section{References}

Ahn, S., \& Choi, J. (2004).Teachers' subject matter knowledge as a teacher qualification: A synthesis of the quantitative literature on students' mathematics achievement. Paper presented at the American Educational Research Association Conference San diego, CA.

Ball, D. L., Lubienski, S. T., \&Mewborn, D. S. (2001). Research on teaching mathematics: The unsolved problem of teachers' mathematical knoweldge. In V. Richardson (Ed.), Handbook of Research on Teaching (Fourth ed., pp. 433-456). Washington D.C.: American Educational Research Association.

Baumert, J., Kunter, M., Blum, W., Voss, T., Jordan, A., Klusmann, U., Krauss, S., Neubrand, M., \& Tsai, Y. (2010). Teachers' mathematical knowledge, cognitive activation in the Classroom, and student progress. American Educational Research Journal, 47 (1), $133-180$.

Beswick, K. (2012). Teachers' beliefs about school mathematics and mathematicians mathematics and their relationship to practice. Educational Studies in Mathematics, 79(1), 127-147.

Boston, M., \& Smith, M. (2009).Transforming secondary mathematics teaching: Increasing the cognitive demands of instructional tasks used in teachers' classrooms. Journal for Research in Mathematics Education, 40(2), 119-156.

Boyd, D., Lankford, H., Loeb, S., Rockoff, J. \& Wyckoff, J. (2008). The narrowing gap in New York City teacher qualifications and its implications for student achievement in high poverty schools. Journal of Policy Analysis and Management, 27(4), $793-818$.

Chauke, W. (2013).A report on analysis of grade 12 students' performance in mathematics paper II examination of 2012.Gauteng Department of Education.

Cohen, L., Manion, L., \& Morrision, K. (2007). Research methods in education (6 $6^{\text {th }}$ d.). New York: Routledge.

Darling-Hammound, L. (2000). Teacher quality and student achievement: A review of state policy evidence. Education Policy analysis Archives, 8(1), 1-44.

De Villiers, M. \& Jugmohan, J. (2012).Learners' conceptualisation of the sine function during an introductory activity using sketchpad at grade 10 level. Educ. Matem. Pesq., São Paulo, 14(1), 9-30.

Department of Education. (2003). National Curriculum Statement Grades 10-12 (General) mathematics. Pretoria: Department of education.

Department of Education. (2008). National Curriculum Statement grades 10-12 (general), Subject assessment guidelines mathematics. Pretoria: Department of education

Ferguson, R.F. (1991). Paying for public education: New evidence on how and why money matters. Harvard Journal on Legislation, 282, 465-498.

Franke, M. (2002). Designing professional development to support generative growth in teachers with different knowledge, skills and identities. Paper presented at the annual meeting of the American Educational Research Association, New Orleans.

Garet, M. S., Porter, A. C., Desimone, L., Birman, B. F., \& Yoon, K. S. (2001).What makes professional development effective? Result from a national sample of teachers. American educational research journal, 38(4), 915-945.

Goe, L. \& Stickler, L.M. (2008). Teacher quality and student achievement: Making the most of recent research. Research \& Policy Brief. Washington, DC: National Comprehensive Centre for Teacher Quality

Greenberg, E., Rhodes, D., Ye, X., \& Stancavage, F. (2004). Prepared to Teach: Teacher preparation and student achievement in eighth-grade Mathematics. American educational research association annual meeting, San Diego, California.

Grossman, P. L. (1990). The making of a teacher: Teacher knowledge and teacher education. New York: Teachers College Press, Columbia University.

Hanssen, C.E. (2006). The Milwaukee Mathematics Partnership: A path model for evaluating teacher and student effects. Paper presented at the MSP Evaluation Summit II, Minneapolis, MN. October 4 - 5, 2006.

Hill, H.C., Rowan, B. \& Ball, D.L. (2005). Effects of teachers' mathematical knowledge for teaching on student achievement. American Educational Research Journal 42(2), 371 - 406.

Hill, H.C., Schilling, S.G \& Ball, D.L. (2004). Developing measures of teachers' mathematical knowledge for teaching. Elementary School Journal, 105, $11-30$, doi:10.1086/428763.

Ingvarson, L., Beavis, A., Bishop, A., Peck, R., \& Elsworth, G. (2004). Investigation of Effective Mathematics teaching and Learning in Australian Secondary Schools. Australia: Australian Council for Educational Research.

Khader, F. R. (2012). Teachers' Pedagogical Beliefs and Actual Classroom Practices in Social Studies Instruction. American International Journal of Contemporary Research 2(1), 73 - 92. 
Kleickmann, T., Richter, D., Kunter, M., Elsner, J., Besser, M., Krauss, S. \& Baumert, J. (2013). Teachers' content knowledge and pedagogical content knowledge: The role of structural differences in teacher education. Journal of Teacher Education 64(1), 90 106

Kupermintz, H. (2002). Teacher Effects as a Measure of Teacher Effectiveness: Construct Validity Considerations in TVAAS (Tennessee Value-Added Assessment System).Centre of the Study of Evaluation Technical Report 563. Los Angeles, CA: National Centre for Research on Evaluation, University of California.

La Marca, P. M. (2001). Alignment of standards and assessments as an accountability criterion. Practical Assessment, Research \& Evaluation, 7(21). [Online] Available: http://PAREonline.net/getvn.asp?v=7\&n=21 (February 21, 2011).

Leinhardt, G., \& Smith, D.A. (1985). Expertise in mathematics instruction: Subject matter knowledge. Journal of Educational Psychology, $77(3), 247-271$

Mogari, D; Kriek, J; Stols, G \& Ogbonnaya, U. I. (2009). Lesotho's students' achievement in mathematics and their teachers' background and professional development. Pythagoras, 70, 3- 15.

Mullens, J. E., Murnane, R. J. \& Willett, J. B. ( 1996). The contribution of training and subject matter knowledge to teaching effectiveness: a multilevel analysis of longitudinal evidence from Belize. Comparative Education Review, 40(2), 139-157.

Odden, A., Borman, G., \& Fermanich, M. (2004). Assessing teacher, classroom, and school effects, including fiscal effects. Peabody Journal of Education, 79(4), 4-32.

Phelps, G. \& Schilling, S. (2004). Developing measures of content knowledge for teaching reading. Elementary School Journal, 105(1), $31-48$.

Rice, J. K. (2003). Teacher quality: Understanding the effectiveness of Teacher Attributes. The Economic Policy institute. [Online] Available: http://www.epinet.org/ content.cfm?id=1500 (November 02, 2009).

Rockoff, J.E., Jacob, B.A., Kane, T.J. \& Staiger, D.O. (2008). Can you recognise an effective teacher when you recruit one? NBER Working paper no. 14485. Cambridge, MA: National Bureau of Economic Research.

Rohaan, E.J., Taconis, R. \& Jochems, W.M.G. (2010). Reviewing the relations between teachers' knowledge and pupils' attitude in the field of primary technology education. International Journal of Technology and Design Education.20, 15-26.

Shulman, L. S. (1986). Those who understand: Knowledge growth in teaching. Educational Researcher, 15(2), 4-14.

Spaull, N. (2012). Education in SA: A tale of two systems. [Online] Available: http://www.politicsweb.co.za/politicsweb / view/politicsweb/en/page71619?oid=323272\&sn =Detail\&pid=71616 (February 11, 2013).

Strauss, R., Sawyer, E., (1986). Some New Evidence on Teacher and Student Competencies, Economics of Education Review, 5(1), 41-48.

Tchoshanov, M. A. (2011). Relationship between teacher knowledge of concepts and connections, teaching practice, and student achievement in middle grades mathematics. Educational Studies in Mathematics, 76(2), 141-164.

The Nuffield Foundation (2013). Trigonometric Functions. Key ideas in teaching mathematics. [Online] Available: http://www.nuffieldfoundation.org/print/3788 (May 03, 2013).

Tuna, A. (2013). A conceptual analysis of the knowledge of prospective mathematics teachers about degree and radian. World Journal of Education, 3(4), 1 - 9 .

Webb, N. L. (2010). Content complexity and depth of knowledge as applicable to research and practice. (In) D. Mogari, A. Mji \& Ogbonnaya, UI (eds). Proceedings of ISTE2010 International Conference: Towards Effective Teaching and Meaningful Learning in MST. pp 1 - 19.

Wenglinsky, H. (2002). How schools matter: The link between teacher classroom practices and student academic performance. Education Policy Analysis Archives, 10 (12). [Online] Available: http://epaa.asu.edu/epaa/v10n12/ (July 12, 2006).

Wessels, H. \& Nieuwoudt, H. (2010). Teacher knowledge and confidence in grade 8 and 9 data handling and probability. In C. Reading (Ed.). Data and context in statistics education: towards an evidence-based society. Proceedings of the eighth international conference on teaching statistics, Ljubljana, Slovenia.

Wilson, S. M., \& Floden, R. E. (2003). Creating effective teachers: concise answers to hard questions. Washington: American Association of Colleges of Teacher Education. 